\title{
Study on Comprehensive Influence of College Sanda Teaching to Students' Mental Health: An Empirical Analysis Based on Network Questionnaires
}

\author{
Caichuan Wang \\ Huanggang Vocational College of Science and Technology, Huanggang 438000, \\ Hubei province, China
}

\begin{abstract}
With the development of network technology and database, network investigation will become one of the main ways of statistical survey. The Internet has provided an unprecedented low cost, fast information channel, also provided convenient information feedback for the information dissemination, and these are the advantages of network investigation. In this paper, we test the impact of college sanda teaching to students' mental health by using network questionnaires. The result shows that Sanda teaching can greatly improve the physical function of college students and improve the quality of college students. Through the big data and network platform, network teaching can optimize the teaching of college physical education; improve the students' interest in sanda.
\end{abstract}

Keywords: Network information, sanda teaching, online survey, college education, mental health, physical will

\section{Introduction}

Among the numerous sociological research methods, survey is one of the most frequently used methods to collect data from a subject. As organizations, universities and individuals on the Internet are widely used, Internet based network survey method gradually becoming popular [1]. Compared with the traditional survey method, the network survey makes the whole process easier, and the distribution of questionnaire information can be completed within a short period of time, the data can also be treated directly on computer access and at low cost [2]. Compared with the traditional network survey party has the incomparable advantages, it is not time and space limit of openness, freedom, equality, universality and direct, and organize the investigation survey is simple and convenient, low cost, a lot of people think that the Internet survey a great alternative to traditional statistical trend, will become the mainstream of the information age and survey data collection methods [3-4]. but the network itself has investigation a lot of problems, on the one hand, the network survey system for professional construction, involves many subjects and large workload on the other hand, the network survey data, data quality level Not one, thus researchers doubt the authenticity of network survey results.

Wushu originated in China, Chinese martial arts has a long history, has a long history and culture and rich content, it is one of the important content of the Sanda, Sanda Sports is a relatively young martial arts sports events, about twenty years of development. In 1979, under the drive of Beijing Sport University and Wuhan Institute of physical education, Sanda movement started in the rapid development of growing up, so far, Sanda has formed mature competition system, training system and teaching system, and the referee rules constantly revised and improved, greatly enriched the Chinese characteristics of athletic sports, promote the development of Chinese Traditional Wushu culture. 
Sanda is also called Sanshou, such as stroke, hand to hand, Baida, split and fighting is on the basis of traditional Wushu, formation and development, competition in the form of direct embodiment, with ornamental, practical and confrontation. In August 2002, the national Ministry of education, National College Physical Education Curriculum Teaching Guide promulgated and implemented, for the Sanda Sports in College Physical Education Curriculum in the setting and promotion provided the policy basis and conditions. It can be seen that the Sanda movement quickly entered the University and got a better development, while driving the traditional sports martial arts culture continues to deepen, its value and characteristics by college students, and promote physical and mental health of College students. The heart rate of male students in a college class of 2014 Sanda elective course class 26 people, blood pressure (systolic / diastolic blood pressure), vital capacity, 100 meters, standing long jump, 1000 meters, 10 meters x 4 run back and forth, body anteflexion in sitting position indicators were tested on their sports hobbies, sports concept, sports motivation and sports will quality degree of questionnaire survey and comparative analysis of index data and get the corresponding results, for colleges and universities to carry out Sanda Teaching to provide valuable theoretical reference.

\section{Review of Literature}

\subsection{Network Data}

Throughout the literature, there is no clear definition of the investigation, in general, for different social purposes; the definition of the investigation is not the same [5]. The definition of the investigation is to study the general scientific research of a representative individual, social organization or group, so as to achieve the purpose of the study of the general or special behavior of the human community. Survey and sample survey. The general survey is a survey of each member, and the sample survey is a scientific sample of the overall study [6]. The discussion of the sampling survey can be traced back to the International Statistical Society of the year, which is advocated in the social investigation should be more use "representative sample" rather than a comprehensive survey. In the later papers, the expression of the "small amount of careful observation" is the preference, which is used as the main advantage of the sample survey. In the end of the study, except on the sampling methods and theoretical research, mostly a statistician's quality of sampling were widely discussed, that is, focusing on the sampling error of classification, statistical effects and the sampling error control.

In general, there are two types of network survey, the first category is the Internet as a means of investigation, in this sense, the network survey is based on customer requirements, through the network technology to obtain the data needed for research, and statistical analysis of the process or the Internet users to make use of the network status of the investigation and analysis process [7]. In addition, the investigation also involves the use of computers for the tool and the use of people to contact the computer to study the general behavior of human beings". The second class for measuring Internet usage survey, in this kind of meaning, Internet survey is refers to the use of Internet measurement, such as the China Internet information center twice a year for China's Internet use survey, the purpose of the survey is measuring site traffic and the website users are also called user, audience, domestic users, commonly known as the quantity, structure and behavior. In addition, the survey also focus on the monitoring and investigation of online advertising, content, including the amount of online advertising, online advertising is clicked, etc.

\subsection{Network Survey}

At present, there are three main ways: first, video conference. It is based on the computer aided access, will be scattered in different regions of the respondents through the Internet video conferencing capabilities to organize virtual organization, under the 
guidance of the host to discuss the investigation method of investigation. Two is active access. This approach is to use a program design language design questionnaire, and then set up the survey questionnaire on the high rate of access to the site or with a higher amount of access to the web site, visitors in accordance with the individual interest, choose whether to participate in a survey [8]. Three is email. The method to relatively complete address list as a sample box, then for every email address in the sample frame issued questionnaire or survey on the Internet links, surveyed received mail after via email to oneself fill return the questionnaire to survey, or directly into the questionnaire link address and to participate in the questionnaire survey methods. In general, the following two methods are the most commonly used network survey method.

1) Timeliness: On the network information transmission speed is very fast, a survey questionnaire through the Internet can be immediately transferred to the rest of the world, within a short period of time can get lots of feedback information, and can immediately generated through statistical analysis results, which ensure the timeliness of survey information, a research firm, which is traditional survey methods cannot match.

2) Objectivity and reliability: Compared with the traditional method of investigation, on the one hand, visitors to the site are generally have some interest in Internet surveys, they need not be confronted by investigators, to answer questions in a relaxed and calm atmosphere, without the intervention of the investigators or other external factors or misleading, which to a large extent ensures that the network according to the results of the objectivity and authenticity [9]. On the other hand, the network investigation has eliminated the traditional data input link, so it can reduce the problems of the data entry process. With the improvement of automatic statistics software, it can be done in a short time to complete the standard statistical analysis, which can guarantee the reliability of network survey results.

3) Low cost and high efficiency: On the Internet, whether it is an investigator or a survey, only have a computer, an Internet interface can communicate with the network. On the web site, the investigators sent a web survey questionnaire to provide relevant information, and then use the computer to the visitors back to the information to quickly organize and analysis, is very convenient [10]. Secondly, network survey and is not influenced by the weather and distance, without printing questionnaire, survey of the most onerous, information collection and input of the key distribution to terminal of a number of network users completed can the unwatched and uninterrupted accept questionnaire, which greatly reduce bodies to investigate the manpower, material force of consumption and, through the network of information exchange, save the traditional survey such as mailing, interviews and spent a lot of time, generally completed the same number of information collection, under the network condition than that under the traditional conditions to spend less time.

4) Wide range: Network survey with the advantages of the network, a wide range of Web sites to investigate, the questionnaire can be filled in any network connection to the site to fill in a questionnaire, not only to increase the efficiency of information dissemination, but also improve the efficiency of the questionnaire.

5) Real-time management: Once the questionnaire is completed, the survey will be entered into the network, the network management of the questionnaire survey, the survey can be at any time to understand the network data collection, processing and analysis, found the problem, at any time to amend the questionnaire.

6) Relative security: Network survey, respondents in independent conditions through the network to answer questions, not only do not have to facing the investigator, and cannot provide personal data, which improve the confidentiality of the data of survey, resulting in a relatively than the traditional method of investigation of the easy access to certain sensitive information. 


\section{Methods}

\subsection{Sample}

The research object is 26 male students in the Sanda elective course, the research time: from March 1, 2015 to June 30, 2015, for a semester teaching of 122 days. Place for the university martial arts Sanda room. In the related website, China HowNet and Baidu consulting related literature, and the existing achievements to sort out, research to find the limitations, and absorb and digest the results of literatures of domestic and foreign Sanda and mental, and puts forward the theoretical framework and hypotheses, and finding a useful reference for the measurement in this paper, we study the concept of, and for the results of the study provide security.

\subsection{Research Methods}

1) Test method: before and after the experiment of 33 male college students heart rate, blood pressure (systolic / diastolic blood pressure), vital capacity, 100 meters, standing long jump, 1000 meters, 10 meters x 4 running to and fro, body ante flexion in sitting position to test and record the good results. The heart rate, the blood pressure (systolic / diastolic blood pressure, vital capacity and body ante flexion in sitting position in the school constitution health testing center test access, 50 meters, standing long jump, 1000 meters, 10 meters $x 4$ shuttle run acquired by Sanda teachers college track and field test, completed the first week of the test data, last week after the completion of the experimental test data.

2) Questionnaire: (1) questionnaire: according to the basic requirements of questionnaire design, view of College Students' Sports Hobbies, sports, sports motivation and sports will quality of research and analysis based on the preparation and the design of the questionnaire; (2) measured questionnaire: questionnaire survey mainly is carries on the investigation to the object of study of college students. The face-to-face interviews, in the form of recycling, and fully guarantee the recovery rate of the questionnaire, and the questionnaire recovery process, a face-to-face conversation with many respondents, 26 questionnaires, 26 were recovered, 26 effective questionnaires, the recovery rate of $100 \%$, efficiency of $100 \%$; (3) the contents of the questionnaire: the questionnaire the questionnaire adopts 5 grade evaluation, sports degree, physical education, sports and sports motivation effect degree of the will of the quality is very good with 5 points, 4 points, 3 points better in general, is not good, not very good 2 points 1 points, higher scores indicate better degree; (4) questionnaire validity test: using Cronbach a to observe the coefficient of internal consistency, in this questionnaire, the $\mathrm{a}=0.84$ coefficient $>0.76$, $\mathrm{P}$ values were less than 0.01 , in line with the requirements of survey validity; (5) questionnaire: the test-retest reliability test, correlation coefficient $r$ Were: $0.92, \mathrm{P}<0.01$, there was statistical significance, reliability and reliability.

3) Comparative study method: comparative study is the thinking process and method to determine the similarities and differences between things. By comparison, the differences and similarities and differences, to find the law, to solve the difficulties, to improve the physical and mental health of College students.

4) Statistical methods: according to the needs of research purposes, this study uses a number of statistical analysis method to analyze the data collected from the questionnaire survey. SPSSI6.0 and Excel2003 were used to analyze the mean comparison, percentage statistics, variance comparison and list ranking method.

5) Logical reasoning: by using the method of comparison, deduction, induction, analysis, reasoning, and other processing methods, the relevant data from the 
statistical significance of the results of logical reasoning, from which to draw the corresponding theoretical conclusions.

\section{Empirical Analysis}

\subsection{Influence to College Students' Physical Function}

Physical function refers to the ability of the body as a whole and its constituent college students each organ system manifestations of life activities. Evaluation and important measure is vital capacity, heart rate and blood pressure. In the case of lung capacity refers to limited time, and then do a maximum inspiratory total maximum capacity of the exhaled gas, is one of the largest lung function activity; heart is resting heart rate, refers to college students in a quiet state per minute The jump in the number of heart; blood pressure refers to the body's blood to college students throughout the body the required pressure. Before the experiment, male college students after physical function (spirometry, heart rate and blood pressure) measurement indicators, input SPSS16.0 statistical software to Analyze Compare Means of processing and calculators to handle. Table 1 The results showed that: in the "vital capacity" comparative indicators, median = 3942.3 after the experiment and standard deviation $=278.8$, median $=3750$ before the experiment and standard deviation $=284.6,192.3 \mathrm{ml}$ increase after the experiment than before the experiment, and statistics Data $\mathrm{F}=6.057, \mathrm{P}=0.017<0.05$, there was a significant statistical significance; in the "heart" comparative indicators, median $=72.27$ and standard deviation $=6.21$, before the experiment median $=$ experiment after 75.96 and standard deviation $=6.52$, after the experiment than before the experiment to reduce 3.69 times / min, and the statistics $\mathrm{F}=4.374, \mathrm{P}=0.042<0.05$, there was a significant statistical significance; in the "systolic" comparative indicators, median $=121.85$ after the experiment and the standard deviation $=5.46$, median $=112.19$ before the experiment and standard deviation $=10.31$, an increase over the previous experiment after experiment $9.66 \mathrm{mmHg}$, and statistical data $\mathrm{F}=17.799, \mathrm{P}=0.000<0.01$, there was a significant statistical significance; in the "diastolic" index comparison, the experiment after median $=$ 80.62 and standard deviation $=5.09$, median $=83.81$ before the experiment and standard deviation $=5.63$, experiment after experiment lower than the previous $3.19 \mathrm{mmHg}$, and statistical data $\mathrm{F}=4.593, \mathrm{P}=0.037<0.05$, there was a significant statistical significance.

Combat Teaching, the whole process is a process of physical exercise, every lesson, the movement of blood circulation, ventricular contraction, a sharp increase in aortic pressure, systolic and diastolic blood pressure adequately exercise, can increase blood vessel elasticity large, easily through the blood, high blood pressure, heart rate, cardiac pump function increased after exercise, the heart can get enough rest, repeatedly teaching cause significantly lower resting heart rate, systolic and diastolic blood pressure accordingly significantly reduced; at the same time in Sanda hit the chest is hit and a greater exercise load and density, increased respiration, slow suction quick call, when the suction with slow inhale slowly widening the thorax so thorax get exercise, breathing exhaled accelerate the movement which led to significantly improved lung capacity. Visible, Combat Teaching can be very significant increase in systolic blood pressure college students significantly improved lung capacity, diastolic blood pressure and heart rate.

Table 1. The Influence of College Students' Physical Function ( $N=26)$

\begin{tabular}{|c|c|c|c|c|c|c|}
\hline Index & $\mathrm{N}$ & Aft. $(\mathrm{X} \pm \mathrm{S})$ & Pre. $(\mathrm{X} \pm \mathrm{S})$ & D-value & $\begin{array}{c}\mathrm{F} \\
\text { value }\end{array}$ & $\begin{array}{c}\mathrm{P} \\
\text { value }\end{array}$ \\
\hline Vital capacity $(\mathrm{ml})$ & 26 & $\begin{array}{c}3942.3 \pm \\
278.8\end{array}$ & $\begin{array}{c}3750 \pm \\
284.6\end{array}$ & 192.3 & 6.057 & 0.017 \\
\hline Heart rate & 26 & $72.27 \pm 6.21$ & $75.96 \pm 6.52$ & -3.69 & 4.374 & 0.042 \\
\hline
\end{tabular}




\begin{tabular}{|c|c|c|c|c|c|c|}
\hline $\begin{array}{c}\text { Systolic blood } \\
\text { pressure (mmHg) }\end{array}$ & 26 & $\begin{array}{c}121.85 \pm \\
5.46\end{array}$ & $\begin{array}{c}112.19 \pm \\
10.31\end{array}$ & 9.66 & 17.799 & 0.000 \\
\hline $\begin{array}{c}\text { Diastolic blood } \\
\text { pressure (mmHg) }\end{array}$ & 26 & $80.62 \pm 5.09$ & $83.81 \pm 5.63$ & -3.19 & 4.593 & 0.037 \\
\hline
\end{tabular}

\subsection{Influence to College Students' Sports Quality}

Quality refers to the movement of human muscle basic capabilities, including speed, strength, stamina, agility and flexibility and so on. Speed of representative projects of 100 meters, the power of representation of projects standing long jump, endurance representative projects of 1000 meters, sensitive representation of the project is $10 \mathrm{~m} \times 4$ shuttle run, pliable representative projects to Sit and Reach. 100 meters is the shortest distance from the international track events, but also "challenge the limits of human speed" speed events; standing long jump is the main development of lower limb explosive jumping ability and sports, is a measure of lower extremity strength sport; 1000 meters is long distance running, refers to a long period of continuous muscle activity resistant long sports; $10 \mathrm{~m} \times 4$ shuttle run is a university student with a marker standing start, exchange markers folded 3 times 10 meters apart at a predetermined location in both ends sensitive project run; Sit and Reach is evaluated at rest torso, waist, hips and other joints may reach the magnitude of flexibility project activities. Enter SPSS16.0 statistical software to Analyze Compare Means of processing and calculators to handle. Table 2 results show: the "100 meters" index comparison, median $=13.14$ after the experiment and standard deviation $=0.53$, median $=13.50$ before the experiment and standard deviation $=0.72$, after the experiment than before the experiment to reduce the $0.36 \mathrm{~s}$, and Statistical data $\mathrm{F}$ $=4.137, \mathrm{P}=0.047<0.05$, there was a significant statistical significance; in the "standing long jump" comparative indicators, the value after the experiment $=240.46$ and standard deviation $=10.89$, before the experiment median $=233.62$ and standard deviation $=9.21$, increased after the experiment than before the experiment $6.84 \mathrm{~cm}$, and the statistics $\mathrm{F}=$ $5.989, \mathrm{P}=0.018<0.05$, there was a significant statistical significance; in the "1000 meters" index comparison, the experiment after median $=231.61$ and standard deviation $=$ 11.79 , before the experiment median $=241.19$ and standard deviation $=17.66$, after the experiment than before the experiment increased $9.58 \mathrm{~s}$, and the statistics $\mathrm{F}=5.289, \mathrm{P}=$ $0.026<0.05$, there was a significant statistical significance; " $10 \mathrm{~m} \times 4$ shuttle run "index comparison, the experiment after median $=12.68$ and standard deviation $=0.97$, median $=$ 13.23 before the experiment and standard deviation $=0.98$, after the experiment than before the experiment to reduce the $0.55 \mathrm{~s}$, and the statistics $\mathrm{F}=4.256, \mathrm{P}=0.044<0.05$, there was a significant statistical significance; in the "Sit and Reach" comparative indicators, median $=14.58$ and standard deviation $=4.73$, before the experiment after experiment median $=10.38$ and standard deviation $=4.15$, after the experiment increase over the previous experiment $4.20 \mathrm{~cm}$, and the statistics $\mathrm{F}=11.534, \mathrm{P}=0.001<0.05$, there was a significant statistical significance.

Sanda teaching in the university, kicking hitting the hand and leg movements are common, to achieve escape hitting each other or hit, are required to increase the curvature of the action, driving the muscles, tendons and ligaments stretch, so that the torso, waist, hips and improve soft tissue stretching and flexibility, which was a significant increase Sit and Reach score. While kicking leg in the process of growing standing long jump leg strength lead to a significant increase achievement; fast hit or dodge the rising speed of 100 meters lead to significantly improved performance; long Sanda Physically demanding, 3-5 minutes is equivalent to 1500 meters Sanda $1000 \mathrm{~m}$ run lead significantly improve performance; the key is to seize the opportunity in Sanda, which we must learn to be sensitive to get rid of the other attacks, in other attacks after the operation to seize the opportunity to give each other a fatal flaw a strike led to $10 \mathrm{~m} \times 4$ shuttle run performance significantly improved. Visible, Combat Teaching can be very significant 
increase of college students Sit and Reach score significantly improved the standing long jump performance, $100 \mathrm{~m}$ achievement, accomplishments and $1000 \mathrm{~m} 10 \mathrm{~m} \times 4$ shuttle run score.

Table 2. The Influence of College Students' Sports Quality ( $\mathrm{N}=26)$

\begin{tabular}{|c|c|c|c|c|c|c|}
\hline Index & $\mathrm{N}$ & Aft. $(\mathrm{X} \pm \mathrm{S})$ & Pre. $(\mathrm{X} \pm \mathrm{S})$ & D-value & $\begin{array}{c}\mathrm{F} \\
\text { value }\end{array}$ & $\begin{array}{c}\mathrm{P} \\
\text { value }\end{array}$ \\
\hline $100 \mathrm{~m}(\mathrm{~s})$ & 26 & $13.14 \pm 0.53$ & $13.50 \pm 0.72$ & -0.36 & 4.137 & 0.047 \\
\hline $\begin{array}{c}\text { Standing long jump } \\
\text { (CM) }\end{array}$ & 26 & $\begin{array}{c}240.46 \pm \\
10.89\end{array}$ & $\begin{array}{c}233.62 \pm \\
9.21\end{array}$ & 6.84 & 5.989 & 0.018 \\
\hline $1000 \mathrm{~m}(\mathrm{~s})$ & 26 & $\begin{array}{c}231.61 \pm \\
11.79\end{array}$ & $\begin{array}{c}241.19 \pm \\
17.66\end{array}$ & -9.58 & 5.289 & 0.026 \\
\hline $10 \mathrm{~m} \times \mathrm{s}(\mathrm{s})$ & 26 & $12.68 \pm 0.97$ & $13.23 \pm 0.98$ & -0.55 & 4.256 & 0.044 \\
\hline Sit and reach (CM) & 26 & $14.58 \pm 4.73$ & $10.38 \pm 4.15$ & 4.20 & 11.534 & 0.001 \\
\hline
\end{tabular}

\subsection{Influence to College Students' Sports Interest and Motivation}

Sports level of interest is students to actively engage in sports activities and priorities understanding of psychological tendencies activity size, with the need to participate in sports activities linked to the intention of activities, college students survey a "degree of interest in the sport," as the survey questions, the more love for sport The higher the score; Sports Concept is the sports university student understanding and judgment of the overall view and the fundamental point of view, it is to recognize sports during physical education methods and determine the success or failure of standards of college students use the questionnaire "exercise on your understanding of the importance of sports "As the survey questions, the importance of physical exercise for understanding the higher the score, the higher; sports motivation is to create and maintain the internal psychological motivation for college students to participate in sports and physical exercises of learning, it is the result of intrinsic motivation inspire college students, which determines Students learn the sport and exercise activities, tendentious, activity intensity and persistence of the effect of physical activity has an important impact on college students survey the use of "your knowledge about the importance of physical exercise motivation" as the survey questions, an important motivation for physical exercise The higher the degree of understanding the higher the score. Enter SPSS16.0 statistical software to Analyze Compare Means of processing and calculators to handle. The results in Table 3 show: the "sport level of interest," Comparison of indicators, the value after the experiment $=3.92$ and standard deviation $=0.89$, median $=3.35$ before the experiment and standard deviation $=0.85$, an increase over the previous experiment after experiment 0.57 points, and statistical data $\mathrm{F}=5.734, \mathrm{P}=0.020<0.05$, there was a significant statistical significance; in the "sports concept" comparative indicators, the value after the experiment $=4.35$ and standard deviation $=0.69$, median before the experiment $=3.46$ and Standard $\mathrm{SD}=0.95$, after the experiment increase over the previous experiment 0.89 points, and the statistics $\mathrm{F}$ $=14.810, \mathrm{P}=0.000<0.01$, there was a significant statistical significance; the more "sports motivation" indicators, the value after the experiment $=4.04$ and standard deviation $=0.82$, median $=3.31$ before the experiment and standard deviation $=0.74$, after the experiment increased 0.73 points over the previous experiments, and statistical data $\mathrm{F}=11.381, \mathrm{P}=$ $0.001<0.01$, there was a significant statistical significance.

Sanda teaching in the university, fighting sparring process must overcome themselves and their opponents, "won his win everything" is the essence of sports, change the "unimportant", "useless" for sports concept; Sanda fighting sports, confrontational national performance quickly leads to the formation and development of direct motivation of college students, promoting their sport motivation to good direction; Sanda fighting 
game exercises, performances and martial arts sparring fighting spirit can inspire college students to Sanda's interests and hobbies, enhance their the degree of interest in sports. Visible, college sports concept can Sanda teaching degree and Sports motivation level is very significant increase of university students, a significant degree of interest in enhancing the sports of college students.

Table 3. The Influence of College Students' Sports Hobbies $(\mathrm{N}=26)$

\begin{tabular}{|c|c|c|c|c|c|c|}
\hline Index & $\mathrm{N}$ & Aft. $(\mathrm{X} \pm \mathrm{S})$ & Pre. $(\mathrm{X} \pm \mathrm{S})$ & D-value & $\begin{array}{c}\mathrm{F} \\
\text { value }\end{array}$ & $\begin{array}{c}\mathrm{P} \\
\text { value }\end{array}$ \\
\hline Sports interest & 26 & $3.92 \pm 0.89$ & $3.35 \pm 0.85$ & 0.57 & 5.734 & 0.020 \\
\hline Sports view & 26 & $4.35 \pm 0.69$ & $3.46 \pm 0.95$ & 0.89 & 14.810 & 0.000 \\
\hline Sports motivation & 26 & $4.04 \pm 0.82$ & $3.31 \pm 0.74$ & 0.73 & 11.381 & 0.001 \\
\hline
\end{tabular}

\subsection{Influence to College Students' Physical Will}

Sports will be people in sports activities consciously set goals, and efforts to overcome all difficulties, and ultimately all mental activities intended target. Willpower is a reflection of the level of development of the human willpower, mainly for consciousness, tenacity, and decisiveness, homemade and initiative. Students voluntarily consciousness refers to the degree of implementation of the overall long-term goals or the pursuit of the task, is able, responsibilities, rights and benefits of a unified, university students survey the use of "you believe that your consciousness level" as the survey questions, on their own consciousness The higher the score, the higher the degree; refers to the perseverance and tenacity indomitable spirit of college students with perseverance to overcome and overcome all difficulties to carry out the will of the decision, college students survey the use of "you believe that your degree of resilience" as the investigation title, their tenacity, the higher the score, the higher the degree; decisiveness means college students did not hesitate to make decisions ability to conduct the behavior of the value of the degree of efficacy, college students survey the use of "you believe that your decisive degree" As the survey questions, their tenacity, the higher the score, the higher the degree; homemade sex, also known as self-control, is that people can not consciously control the size of their own ability to meet the stated objectives of emotions and actions, college students survey the use of "you think their degree of self "as the survey questions, on their own, the higher the score, the higher the degree of self; the initiative refers to the individual needs of the target behavior, motivation, ideals, aspirations and values-driven, college students using questionnaires" You extent that their initiative "as the survey questions, on their own initiative, the higher the score, the higher the degree; sports will score is the sum of the scores consciousness, tenacity, determination, and self-initiative, the higher the score sports Will better. Enter SPSS16.0 statistical software to Analyze Compare Means Means of processing and calculators to handle. Table 4 The results showed that: in the "consciousness" comparative indicators, the value after the experiment $=4.23$ and standard deviation $=0.71$, median $=3.62$ before the experiment and standard deviation $=$ 0.70, an increase over the previous experiment after experiment 0.61 points, and Statistical data $F=9.938, P=0.003<0.01$, there was a significant statistical significance; the more "tenacity" of indicators, the value after the experiment $=3.58$ and standard deviation $=0.76$, median before the experiment $=2.96$ and Standard SD $=0.96$, after the experiment increased 0.62 points over the previous experiments, and statistical data $\mathrm{F}=$ $6.598, \mathrm{P}=0.013<0.05$, there was a significant statistical significance; the more "decisiveness" indicators, the value after the experiment $=3.77$ and Standard $\mathrm{SD}=0.86$, the value before the experiment $=3.12$ and standard deviation $=1.11$, after the experiment increased 0.65 points over the previous experiments, and statistical data $\mathrm{F}=5.640, \mathrm{P}=$ $0.021<0.05$, there was a significant statistical significance; in the "self-sex" index comparison, the experiment after median $=4.46$ and standard deviation $=0.51$, median $=$ 
3.77 before the experiment and standard deviation $=0.86$, an increase of 0.69 points before the experiment after experiment, and statistics $\mathrm{F}=12.423, \mathrm{P}=0.001<0.01$, there was a significant statistical significance; in the "initiative" comparative indicators, the value after the experiment $=4.00$ and standard deviation $=0.75$, median $=3.35$ before the experiment and standard deviation $=0.98$, an increase over the previous experiment after experiment 0.65 points, and the statistics $\mathrm{F}=7.335, \mathrm{P}=0.009<0.01$, there was a significant statistical significance; in the "sports will" comparative indicators, the value after the experiment $=20.04$ and $\mathrm{SD}=3.30$, the value before the experiment $=16.81$ and standard deviation $=4.41$, after the experiment increased 3.23 points over the previous experiments, and statistical data $\mathrm{F}=8.939, \mathrm{P}=0.004<0.01$, there was a significant statistical significance.

Sanda teaching in the university, fighting to hit from failure to success, from success to overcome self, college students are required to overcome the difficulties and to overcome the difficulties of confidence and perseverance, and improve their self, self-awareness, initiative, tenacity and decisiveness, will enhance their sport. Visible, Combat Teaching can be very significant increase Student Sports will, very significant homemade sex significantly improve college students, consciousness and initiative, significantly increase resilience and decisiveness.

Table 4. The Influence of College Students' Physical Will ( $N=26)$

\begin{tabular}{|c|c|c|c|c|c|c|}
\hline Index & $\mathrm{N}$ & Aft. $(\mathrm{X} \pm \mathrm{S})$ & Pre. $(\mathrm{X} \pm \mathrm{S})$ & D-value & F value & P value \\
\hline Consciousness & 26 & $4.23 \pm 0.71$ & $3.62 \pm 0.70$ & 0.61 & 9.938 & 0.003 \\
\hline Tenacity & 26 & $3.58 \pm 0.76$ & $2.96 \pm 0.96$ & 0.62 & 6.598 & 0.013 \\
\hline Decisive & 26 & $3.77 \pm 0.86$ & $3.12 \pm 1.11$ & 0.65 & 5.640 & 0.021 \\
\hline Self-made & 26 & $4.46 \pm 0.51$ & $3.77 \pm 0.86$ & 0.69 & 12.423 & 0.001 \\
\hline Initiative & 26 & $4.00 \pm 0.75$ & $3.35 \pm 0.98$ & 0.65 & 7.335 & 0.009 \\
\hline Sports will & 130 & $20.04 \pm 3.30$ & $16.81 \pm 4.41$ & 3.23 & 8.939 & 0.004 \\
\hline
\end{tabular}

\section{Discussion}

There are many problems in the development of Sanda Teaching in Colleges and universities. The main conclusion: College Sanda Teaching can significantly improve students significantly increased systolic blood pressure, diastolic pressure and heart rate, vital capacity, and constantly improve the college students' physical function was significantly increased; sitand reach college students, significantly improve the standing long jump, 100 meters, 1000 meters and 10 grades grade $\mathrm{m} \mathrm{x} 4$ shuttle run results, improve college students sports quality; greatly improve students' physical education degree and the motivation level, significantly improve the degree of students' interest in sports; very significant to improve college students' sports will, very significant to improve college students' self - consciousness and initiative, significantly improve the tenacity and decisiveness.

Sanda Teaching in Colleges and universities can greatly improve the systolic blood pressure, significantly improve the vital capacity, diastolic blood pressure and heart rate, and constantly improve the physical function of college students.The college Sanda Teaching is very significant to improve the college students body anteflexion in sitting position scores, significantly improved the result of standing long jump, 100 meter record, 1000 meters of achievement and 10 meters x 4 shuttle run performance, and constantly improve the quality of the student.Sanda Teaching in Colleges and universities can greatly improve the degree of physical education and sports motivation of college students. Sanda Teaching in Colleges and universities can greatly improve the students' sports will, and it is very significant to improve the students' self-control, self - consciousness and initiative. 


\section{References}

[1] W. Dai and L. Fan, "Discussion about the Pros and Cons and Recommendations for Multimedia Teaching in Local Vocational Schools", Physics Proceeding, vol. 33, (2012), pp. 1144-1148.

[2] S. J. Hua and L. Hong, "Explore the Effective Use of Multimedia Technology in College Physics Teaching", Energy Proceeding, vol. 17, (2012), pp. 1897-1900.

[3] M. Sigala, "Investigating the role and impact of Geo-visualization and Geo-collaborative portals on collaborative e-learning in tourism education”, Journal of Hospitality, Leisure, Sport \& Tourism Education, vol. 11, (2012), pp. 50-66.

[4] M. Hu and S. Xu, "Research of Multimedia Teaching on Principles of Management", IERI Proceeding, vol. 2, (2012), pp. 666-670.

[5] C. Wei and Y. Tao, "Application of Multimedia-Aided Project-Teaching Mode in Cultural Education", IERI Proceeding, vol. 2, (2012), pp. 538-542.

[6] C. Krstev and A. Trtovac, "Teaching Multimedia Documents to LIS Students", The Journal of Academic Librarianship, vol. 40, no. 2, (2014), pp. 152-162.

[7] Y. Huang and S. Backman, "Experiencing student learning and tourism training in a 3D virtual world: An exploratory study”, Journal of Hospitality, Leisure, Sport \& Tourism Education, vol. 13, (2013), pp. 190-201.

[8] A. K. Kim and J. Davies, "A teacher's perspective on student centered learning: Towards the development of best practice in an undergraduate tourism course", Journal of Hospitality, Leisure, Sport \& Tourism Education, vol. 25, (2014), pp. 6-14.

[9] H. Janta and P. Lugosi, "Migrant networks, language learning and tourism employment", Tourism Management, vol. 33, no. 2, (2012), pp. 431-439.

[10] C. Zhang and X. Chen, "Use of Multimedia in Gross Infective Pathogen Experimental Teaching", Proceeding Engineering, vol. 37, (2012), pp.64-67. 